\section{Opportunities to improve global health: using the strengths of the BJSM community to change lives for the better}

\author{
Steve Aspinall, Allan Munro
}

One of the founding principles of the British Association of Sport Rehabilitators and Trainers-BASRaT-was to improve the health of patients and the public with a clear focus on exercise for health and exercise rehabilitation. That goal has never been more important than it is today and it provided the inspiration for our cover image (figure 1 ). In the midst of a pandemic, attention will be inevitably and increasingly focused on the health of our respective nations and bring into sharp relief the challenges we face as an international community of medical and healthcare professionals. An effective response to these challenges will involve us all working together to improve our knowledge and to identify the best way to translate that into real improvements in public health.

Across the UK, organisations and professional bodies representing numerous healthcare professions have already started working more collaboratively, with the goals of the individual profession being subservient to finding ways to optimise rehabilitation and the prevention of ill health. Both the Arthritis and Musculoskeletal Alliance (ARMA) (http://arma.uk.net) and the Community Rehabilitation Alliance are just two examples of this in the UK. These alliances cut across professional boundaries, integrate healthcare systems and support the rights of patients and the public to achieve their potential and live as well as possible. This BASRaT-guided issue of the BJSM reflects those goals too.

\section{WHAT'S NEW IN THIS BASRAT ISSUE?}

In 2018, WHO released the Global Action Plan for Physical Activity, ${ }^{1}$ an evidencebased and comprehensive public health plan fit for the international stage. Global physical activity colossus, Professor Michael Pratt from the University of

School of Health and Society, University of Salford, Salford, UK

Correspondence to Steve Aspinall, School of Health and Society, University of Salford, Salford M6 6PU, UK ; S.J.Aspinall@salford.ac.uk

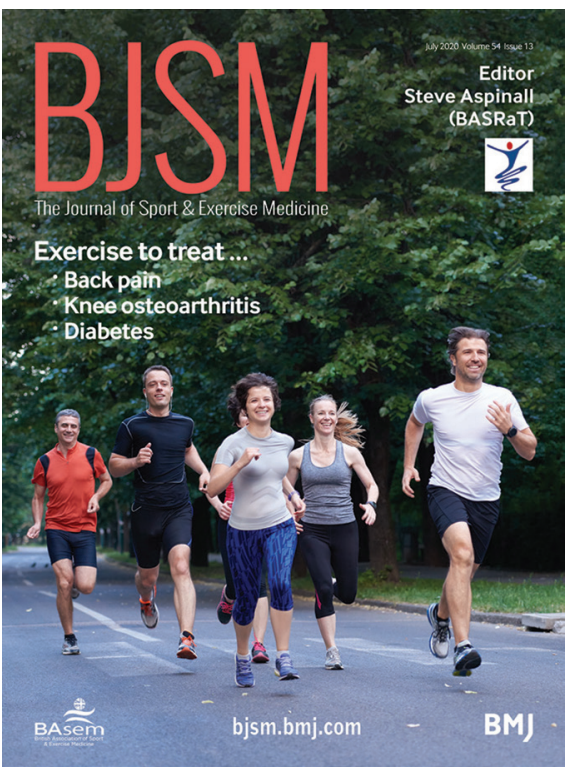

Figure 1 The British Association for Sport Rehabilitators and Trainers has a clear focus on exercise for health and rehabilitation.

California, San Diego, discusses where we are now, what has been achieved in the past 2 years, and even more crucially, where we should go from here (see page 760). As well as discussing the sectors that need to be involved in tackling the global pandemic of physical inactivity, they recommend how both research communities and public health agencies can move us forward to better health with population-scale initiatives.

Questions that frequently come up, both in the literature and in discussion with patients, is how much exercise is enough, what is the optimal level of exercise for health and could too much exercise be harmful? Drs Johannes and Martin Burtscher (University of Innsbruck, Austria) have scrutinised the evidence and some of the answers, based on large studies examining exercise and longevity, might just surprise you (see page 759). They look at specific exercise volumes and highlight the different levels needed to reduce
About BASRaT

The British Association of Sport Rehabilitators and Trainers (BASRaT) is the UK regulator for sport and exercise rehabilitators and an advocate of the multidisciplinary healthcare team. Improving public health by lifestyle and physical activity is a key part of our mission and supporting this, we are proud to be a member of both ARMA and the Community Rehabilitation Alliance. BASRaT guides sport rehabilitators on all aspects of their role and responsibilities, ensuring public protection, professional competency and continued professional development.

The BASRaT register of sport rehabilitators has been approved as an accredited register by the Professional Standards Authority for Health and Social Care. For more detail please visit us at www.basrat.org

cause-specific and all-cause mortality. This information also needs to be considered in the context of being patient-specific in addition to linking into behaviour change models and where a patient is on their exercise and physical activity journey.

As clinicians, we spend a lot of time encouraging patients to sit less and move more. Do different patterns of physical activity during the day (morning exercise, afternoon exercise bouts or prolonged sitting) improve distinct aspects of brain function in different ways? In their randomised cross-over trial, Dr Michael Wheeler and an all-star international author team answer the question and explain why we want people to interrupt prolonged sitting to improve cognition (see page 776).

Supporting our advice to patients about running and based on their systematic review and meta-analysis, public health professor Zeljko Pedisic and colleagues (University of Victoria, Melbourne) have provided an excellent infographic detailing the all-cause, cardiovascular and cancer mortality benefits of running (see page 817 ). Supporting this, do you also want to improve your runners' performance but you aren't sure how to do it? Sports physiotherapist James Alexander and colleagues have the answers in an easy-to-understand guide to strength training for runners, an area that even experienced clinicians can find confusing (see page 813 ). They provide the facts and bust common myths in a practical guide. 
Low back pain (LBP) is the leading global cause of years lived with disability ${ }^{2}$ and represents a considerable treatment challenge, with one-size-fits-all approaches being frequently employed clinically. In their multicentre randomised controlled trial, Ireland's Dr Mary O'Keeffe and colleagues compare an individualised approach called cognitive functional therapy with group-based exercise and education for CLBP and provide valuable insight into how we might need to refine our approach to CLBP (see page 782). Adding further key information to this area, a systematic review and network meta-analysis by Dr Rongzhong Huang and colleagues from Kunming, China compare multiple treatments for the prevention of LBP and identify the strengths of current treatments and the areas of the exercise prescription that we need to investigate further (see page 766).

Systematic reviews are a crucial tool to inform clinicians and their decisions, but how do you know the information they provide can be relied on? In their highly informative two-part series, sports physiotherapist Fionn Büttner and colleagues highlight why study quality and risk of bias are not the same and why the latter is so important-you can have a high quality study with a high risk of bias. They go on to provide an indispensable checklist for authors, peer reviewers and editorial staff.

Other must-reads in this issue include those on accurate information exchange, exercise prescription parameters and markers of cardiovascular health in patients with knee osteoarthritis (OA), telehealth and knee OA, physical activity during and after pregnancy, injury prevention in team sports, the management of active individuals with type 1 diabetes and the many shades of adiposity. All should add to your knowledge base and help us to optimise rehabilitation and prevent ill health on a global scale.

Funding The authors have not declared a specific grant for this research from any funding agency in the public, commercial or not-for-profit sectors.
Competing interests None declared.

Patient consent for publication Not required.

Provenance and peer review Commissioned; internally peer reviewed.

(c) Author(s) (or their employer(s)) 2020. No commercial re-use. See rights and permissions. Published by BMJ.

(D) Check for updates

To cite Aspinall S, Munro A. Br J Sports Med 2020:54:757-758

Accepted 26 May 2020

Br J Sports Med 2020;54:757-758.

doi:10.1136/bjsports-2020-102763

\section{REFERENCES}

1 World Health Organization. Global action plan on physical activity 2018-2030: more active people for a healthier world (Licence: CC BY-NC-SA 3.0 IGO). Geneva, 2018.

2 GBD. 2017 disease and injury incidence and prevalence Collaborators. global, regional, and national incidence, prevalence, and years lived with disability for 354 diseases and injuries for 195 countries and territories, 1990-2017: a systematic analysis for the global burden of disease study 2017. The Lancet 2018;392:1789-858. 